University of Windsor

Scholarship at UWindsor

$9-2-1996$

\title{
Ontogeny of visual and mechanosensory structure and function in atlantic menhaden Brevoortia tyrannus
}

Dennis M. Higgs

University of Windsor

Lee A. Fuiman

Follow this and additional works at: https://scholar.uwindsor.ca/biologypub

Part of the Biology Commons

\section{Recommended Citation}

Higgs, Dennis M. and Fuiman, Lee A., "Ontogeny of visual and mechanosensory structure and function in atlantic menhaden Brevoortia tyrannus" (1996). Journal of Experimental Biology, 12, 199, 2619-2629.

https://scholar.uwindsor.ca/biologypub/94

This Article is brought to you for free and open access by the Department of Biological Sciences at Scholarship at UWindsor. It has been accepted for inclusion in Biological Sciences Publications by an authorized administrator of Scholarship at UWindsor. For more information, please contact scholarship@uwindsor.ca. 


\title{
ONTOGENY OF VISUAL AND MECHANOSENSORY STRUCTURE AND FUNCTION IN ATLANTIC MENHADEN BREVOORTIA TYRANNUS
}

\author{
DENNIS M. HIGGS ${ }^{*} \dagger$ AND LEE A. FUIMAN \\ Department of Marine Science, The University of Texas at Austin, Marine Science Institute, \\ 750 Channelview Drive, Port Aransas, TX 78373, USA
}

Accepted 2 September 1996

\begin{abstract}
Summary
The importance of visual, mechanoreceptive and auditory inputs to escape responses was examined in larvae of the Atlantic menhaden (Brevoortia tyrannus) presented with a simulated predatory stimulus. Ontogenetic changes in the retina, superficial neuromasts and auditory bullae were examined in concert with behavioral trials in which sensory inputs were selectively blocked. Menhaden larvae showed a decrease in cone photoreceptor density and first developed rod photoreceptors when their total length $(T L)$ reached $8-10 \mathrm{~mm}$; they began summing photoreceptive inputs at 12-14 $\mathrm{mm} T L$. Inflation of the auditory bullae was complete by $15 \mathrm{~mm} T L$. The proliferation of superficial neuromasts varied depending on their location, with cephalic superficial neuromasts decreasing in number

larvae). When visual inputs were blocked, responsiveness was lower than in control larvae, but still increased ontogenetically, while reactive distance showed no difference between control larvae and those lacking visual information. When neuromasts were ablated, ontogenetic increases in responsiveness and reactive distance were absent. Inflation of the auditory bullae had no discernible effect on behavior. The anatomical and behavioral results suggest that both vision and mechanoreception are used to trigger a response to a looming predatory stimulus and that mechanoreception, but not vision, contributes to the timing of the response. Ontogenetic improvements in performance are attributed mainly to neuromast proliferation and not to ontogenetic changes in the retina.
\end{abstract} beginning at $19 \mathrm{~mm} T L$ and numbers of trunk neuromasts continuing to increase throughout the larval period. In behavioral trials, responsiveness and the reactive distance to the approaching probe increased with increasing larva total length when all sensory inputs were available (control

Key words: Brevoortia tyrannus, menhaden, vision, mechanoreception, ontogeny, larva, sensory development, behavior, functional morphology.

\section{Introduction}

Many species of marine fish hatch with very limited sensory capabilities and do not develop some important sensory structures until later in the larval period (Blaxter, 1986). During this life stage, these fish must still find food, evade predators and cope with other challenges to their survival. Predation is an important context in which to examine the functional consequences of ontogenetic changes in sensory morphology since predation is a major source of mortality in larval fishes (Hunter, 1981; Bailey and Houde, 1989) and their susceptibility to predators changes during the larval period (Bailey, 1984; Bailey and Batty, 1984; Folkvord and Hunter, 1986; Fuiman, 1989). The vulnerability of larvae to predation is contingent upon the probabilities that a larva will be detected, attacked and captured by a predator (Fuiman, 1989; Fuiman and Magurran, 1994). The probability of capture is the most easily quantified of these and is partly determined by the ability of the larva to respond to and escape from an attacking predator. Larval responsiveness and escape ability increase during ontogeny in many species (Webb, 1981; Folkvord and Hunter, 1986; Pepin et al. 1987; Fuiman, 1989, 1994). One important determinant of escape success is the ability of a larva to respond to an attacking predator at the appropriate time, neither too early nor too late (Fuiman, 1993). Its sensory systems provide the necessary information about the approaching predator for a larva to judge whether to respond and at what moment. Thus, ontogenetic changes in sensory morphology may be expected to have important consequences for susceptibility to predatory attack and, hence, survival.

Although many studies have examined the anatomical development of sensory systems in fishes (Blaxter and Jones, 1967; O'Connell, 1981; Pfeiler, 1989; Webb, 1989; Hagedorn and Fernald, 1992; Mukai et al. 1992), the functional

*Present address: Department of Molecular and Cellular Biology, Life Sciences South 444, University of Arizona, Tucson, AZ 85721, USA (e-mail: dhiggs@ccit.arizona.edu).

$\dagger$ To whom reprint requests should be addressed. 


\section{D. M. Higgs And L. A. Fuiman}

consequences of this development are not well understood. A large body of research has been conducted on Atlantic herring (Clupea harengus) in this regard. Inflation of the auditory bullae in herring coincides with a dramatic increase in responsiveness to predatory attacks (Blaxter and Batty, 1985; Blaxter and Fuiman, 1990). The visual (Blaxter and Fuiman, 1990; Blaxter, 1991) and mechanoreceptive (Blaxter and Fuiman, 1989, 1990; Blaxter, 1991) systems have also been implicated in responses to predatory stimuli in herring, although the importance of ontogenetic changes is less clear for these systems. Similarly detailed data are not available for other species. Responsiveness to electrical, acoustico-lateralis, visual and tactile stimuli increases ontogenetically in coho salmon (Oncorhynchus kisutch) (Taylor and McPhail, 1985), although it is unclear precisely how this relates to sensory morphology in this species.

The present study examines the development of sensory morphology and behavioral responsiveness in larval Atlantic menhaden (Brevoortia tyrannus), a close relative of Atlantic herring. Ontogenetic changes in auditory bullae, neuromast proliferation and retinal morphology are detailed. The auditory bullae are paired gas-filled sacs that transmit variations in sound pressure to the inner ear and lateral-line canal in menhaden and other clupeoid fishes (Allen et al. 1976). All clupeoids hatch without a bulla, acquiring this structure and filling it with gas during the larval period (Allen et al. 1976). Menhaden hatch with superficial neuromasts as the only end organs of the lateral-line system. When larvae reach a total length $(T L)$ of $14-16 \mathrm{~mm}$, cephalic superficial neuromasts begin to be subsumed into canals in menhaden (Hoss and Blaxter, 1982). Clupeoids have no lateral line canals on the trunk (Blaxter and Hunter, 1982); therefore, the only lateralline end organs on the trunk are superficial neuromasts. Clupeoids, like most other teleosts, hatch with a retina containing only cones. Rods do not develop until later in the larval period (Blaxter, 1986).

The responses of larvae to an artificial stimulus were examined ontogenetically to determine how these changing sensory structures affect behavioral function. During behavioral trials, sensory stimuli were selectively withheld from larvae to determine which sensory systems play a role in the behavior under study. We also compared the behavioral acuity in control larvae with the visual acuity calculated from the anatomy of the eye. The implications of ontogenetic changes in anatomy and behavior are also discussed in relation to the ecology of this species.

\section{Materials and methods}

Atlantic menhaden Brevoortia tyrannus (Latrobe) embryos were received from the National Marine Fisheries Service, NOAA Southeast Fisheries Center, Beaufort Laboratory on 11 March 1994. Larvae were reared at the Marine Science Institute of the University of Texas at Austin in 1501 conical tanks with a recirculating biological filter. Water temperature in the rearing tanks was maintained between 20 and $22^{\circ} \mathrm{C}$ and salinity was 29-31\%o. Larvae were initially fed rotifers (Brachionus plicatilis) and were gradually switched to brine shrimp (Artemia sp.) nauplii at 10 days post-hatching. Larvae were not used for experiments until 5 days after hatching. Atlantic menhaden larvae began to feed by 3 days after hatching, completely absorbed their yolk before day 5 and metamorphosed to juveniles at 150-160 days after hatching at these temperatures. All larvae used in behavioral trials had darkly pigmented eyes.

\section{Anatomy}

Five larvae were sampled from the rearing tank daily and their total length was measured under a dissecting microscope connected to a video measurement system. Each fish was assessed for the presence or absence of gas in the bullae. This was easy to ascertain as the larvae were transparent and the gas in the bullae formed a reflective bubble. After all fish had been examined, the percentage of fish with inflated bullae was calculated for each $1 \mathrm{~mm}$ size class (Fig. 1).

The proliferation and distribution of superficial neuromasts was examined following the protocols of Blaxter et al. (1983) and Margulies (1989). Larvae were anesthetized with MS-222 and placed in a $0.05 \%(\mathrm{w} / \mathrm{v})$ solution of the vital stain Janus Green in $30 \%$ o sea water for $20 \mathrm{~min}$. After removal from this solution, larvae were gently rinsed in sea water and examined under a dissecting microscope. The outline of each larva was traced through a camera lucida and the position of each stained neuromast was marked on this outline. Composite estimates of neuromast numbers were made on the basis of 3-6 fish in each $1 \mathrm{~mm}$ size class. Composite numbers, rather than averages, were used owing to the vagaries of the staining procedure (Margulies, 1989). Cephalic and trunk neuromasts were tallied separately. Only neuromasts on the left side of the body were counted, and care was taken always to lie a larva on its right side to protect the neuromasts being examined.

Larvae were prepared for retinal examination by anesthetizing with MS-222 and fixing in Bouin's fixative for $24 \mathrm{~h}$. Total length and eye and lens diameters were measured after fixation. Heads of larvae were then embedded in paraffin and sectioned transversely at $6 \mu \mathrm{m}$. Retina sections were stained in Hematoxylin and Eosin using standard methods (e.g. Carleton, 1957).

The density of different cell types in the retina was determined from the stained sections. Cone cell ellipsoids, nuclei in the outer nuclear layer (ONL) and ganglion cells were counted over $0.02,0.05$ or $0.1 \mathrm{~mm}$ transects, depending on the size of the eye. Following the protocol of Gundersen (1977), cells overlapping the left side of the transect line were not counted but those overlapping the right side were. The counts made in this manner were not corrected for counting bias as there is still controversy over the best method of correction (reviewed in Clarke and Oppenheim, 1995) and ontogenetic changes in, rather than precise determination of, cell numbers were of interest in the present study. Cone ellipsoids do increase in size during ontogeny, leading to a possible overestimation of cone density in this study. As cone density 
decreased rather than increased, however, we do not feel this possible bias significantly affected these data. All counts were converted to numbers of cells per $0.1 \mathrm{~mm}$ along this transect. Rod densities were estimated indirectly using the ratio of ONL nuclei to cone ellipsoids. When this ratio exceeded unity, rods were assumed to be present (Blaxter and Jones, 1967). The summation of photoreceptor cells onto ganglia was estimated by dividing ganglion cell density by ONL nuclear densities. When this ratio exceeded unity, each ganglion cell was presumed to be receiving input from more than one photoreceptor (Boehlert, 1979). The final retinal attribute estimated was the histological acuity, expressed as minimum separable angle $(\alpha)$. This was calculated as:

$$
\alpha=\arcsin (0.22 / f n),
$$

where $f$ is the focal length of the eye and $n$ is the number of cones per $0.1 \mathrm{~mm}$ of the retina (Neave, 1984). The focal length of the eye was estimated by multiplying the lens radius by Mathiessen's ratio (2.55; Matthiessen, 1880). Equation 1 represents the theoretically maximal acuity that the eye can achieve.

\section{Behavior}

Trials were conducted under an infrared-sensitive video camera with images sent to a video recorder in an adjoining room. Two larvae, in a Petri dish (dimensions in Table 1), were placed on an acrylic platform beneath the camera. Illumination was provided from above via a fluorescent ring-illuminator and from below during dark trials via an infrared light source. The infrared light source consisted of an incandescent bulb in a sealed lamp housing fitted with a Kodak safelight filter (no. 11, catalog no. 107 9326). This filter blocks wavelengths below $780 \mathrm{~nm}$, and the light was assumed to be invisible to the larvae (Blaxter, 1968; Batty, 1983). The platform and dish were surrounded by a black curtain to minimize disturbance of the larvae and to eliminate light from a nearby video monitor.

Behavioral trials were conducted under four sets of conditions, designed to isolate the individual sensory systems. To test the effects of neuromast blockage, enough $15 \mathrm{mmoll}^{-1}$ streptomycin sulfate was added to the Petri dishes to result in a final concentration of $5 \mathrm{mmoll}^{-1}$ streptomycin (see Table 1 for actual volumes). This treatment rapidly ablates superficial neuromasts of fishes (Wersäll and Flock, 1964; Kaus, 1987; Blaxter and Fuiman,

Table 1. Experimental conditions used for Atlantic menhaden behavioral trials

\begin{tabular}{lccc}
\hline $\begin{array}{l}\text { Approximate } \\
\text { larva length } \\
(\mathrm{mm})\end{array}$ & $\begin{array}{c}\text { Container } \\
\text { diameter } \\
(\mathrm{mm})\end{array}$ & $\begin{array}{c}\text { Water volume } \\
\text { before addition } \\
(\mathrm{ml})\end{array}$ & $\begin{array}{c}\text { Volume } \\
\text { after addition } \\
(\mathrm{ml})\end{array}$ \\
\hline $4-8$ & 35 & 4 & 6 \\
$8-14$ & 60 & 10 & 15 \\
$14-22$ & 100 & 30 & 45
\end{tabular}

Depending on the treatment, sea water (controls) or streptomycin was added to the containers after acclimation, resulting in the volumes in the last column.
1989) but does not affect the inner ear (Matsuura et al. 1971). Larvae treated in this manner were tested in the light $\left(30 \mu \mathrm{Em}^{-2} \mathrm{~s}^{-1}\right)\left(\mathrm{E}\right.$, Einstein; $1.0 \mu \mathrm{E}=6 \times 10^{17}$ photons $)$ during the daytime (light-strep treatments) and in the dark $\left(<0.01 \mu \mathrm{E} \mathrm{m}^{-2} \mathrm{~s}^{-1}\right)$ at night (dark-strep treatments). A few additional fish were left in the streptomycin solution for $24 \mathrm{~h}$ to make certain that this treatment was not toxic and did not disrupt the equilibrium of the larvae. No detrimental effects were observed in fish exposed to streptomycin for $24 \mathrm{~h}$. Sham experiments using sea water instead of streptomycin were conducted to test the behavioral responses of larvae with intact neuromasts. Larvae exposed to the seawater addition were tested in the light $\left(30 \mu \mathrm{Em}^{-2} \mathrm{~s}^{-1}\right)$ during the day (light-controls) and in the dark $\left(<0.01 \mu \mathrm{E} \mathrm{m}^{-2} \mathrm{~s}^{-1}\right)$ at night (darkcontrols). There were no apparent differences in spontaneous activity levels in larvae tested in the light and dark. Daytime trials were conducted between 14:00 and 17:00 h, and night trials were conducted between 20:00 and 22:00 h. By comparing the responses of larvae in the light-strep versus light-control treatments, the importance of neuromast input could be assessed. By comparing dark-controls with light-controls, the role of vision could be assessed. Examination of dark-strep larvae revealed the role other sensory systems, such as the inner ear, could have played in the behavioral responses.

For the behavioral trials, larvae were carefully removed from the rearing container and left undisturbed in their individual Petri dishes for at least $2 \mathrm{~h}$ before being placed on the behavior platform. Either streptomycin (strep treatments) or sea water (controls) was added to the dishes and the fish were left undisturbed for an additional $5 \mathrm{~min}$. Larvae were then approached with an artificial predatory stimulus and their behavioral responses recorded. The predatory stimulus, modeled after other studies (Yin and Blaxter, 1987; Blaxter and Fuiman, 1989), was a probe constructed of a dissecting pin having a $1.1 \mathrm{~mm}$ diameter spherical head. The pin was attached to a glass Pasteur pipette bent at $90^{\circ}$. The probe was manually advanced towards a larva until it responded or was touched by the probe. The use of the manually advanced probe, rather than a mechanically advanced one, did present some problems. Probe speed tended to be faster for larger larvae but there was no difference in probe speed between responding and nonresponding larvae $(P=0.91)$. There was a significant difference in probe speed between treatments $(P=0.05)$ but only because of the decreased speed in light-strep treatments (Bonferroniadjusted $\alpha=0.004, P=0.001)$. The use of a manually advanced probe was preferred over a mechanical probe as it allowed more precise orientation of the probe to actively swimming larvae.

During analysis of video recordings from the behavioral trials, three criteria had to be met for a trial to be scored: (1) the probe approached the larva from the front, (2) the larva made no swimming movements for at least five video frames $(0.17 \mathrm{~s})$ before the probe began to move, and (3) if the larva responded to the approaching probe, its movement was too fast to be captured on one video frame $(0.03 \mathrm{~s})$. This last criterion was used to differentiate startle responses from normal swimming movements. Each larva was scored for whether or not it responded to the probe before it was touched and, of those that 
did respond at a distance, at what distance the response occurred. This last measurement was termed the 'reactive distance' of the larva. If a larva failed to respond even after being touched by the probe, it was not used in the analyses.

\section{Data analysis}

Developmental changes in anatomy and behavior were measured on a scale of total length, rather than age, because size is a better gauge of developmental progress (Gerking and Rausch, 1979; L. A. Fuiman, K. R. Poling and D. M. Higgs, in preparation). Total lengths of larvae used for retinal morphology were corrected for shrinkage due to fixation using the following equation:

$$
\text { total length }=(\text { fixed length }+0.73) / 0.97 .
$$

This relationship was determined empirically in our laboratory for menhaden larvae $\left(r^{2}=0.99\right)$. Total lengths of larvae used in the behavioral trials were measured from the video recordings.

Retinal development was analyzed using piecewise regression (Wilkinson, 1992) where appropriate. This was carried out to determine objectively the size at which the rate of development changed appreciably. The mean size at which $50 \%$ of the larvae had filled bullae was determined with a nonlinear estimation procedure (Fig. 1; Wilkinson, 1992).

In behavioral trials, larvae were scored as either responding or not responding, a binary variable. Responsiveness, the proportion of larvae responding, was calculated for $3 \mathrm{~mm}$ size classes to increase sample sizes and statistical power. Ontogenetic changes in responsiveness were analyzed within each treatment by weighted linear regression. The proportion responding in each $3 \mathrm{~mm}$ size class was weighted by the square root of the inverse of the binomial variance to normalize the distribution (Wilkinson, 1992). Regression coefficients for responsiveness in dark-control, light-strep and dark-strep treatments were compared with the responsiveness in the lightcontrols using $t$-tests (Zar, 1984). Reactive distance, a continuous variable, was examined ontogenetically using simple linear regression within treatments. Regression coefficients for dark-control, light-strep and dark-strep treatments were again compared with light-controls using $t$-tests (Zar, 1984). Significance levels for $t$-tests were corrected using the Bonferroni adjustment for mutliple tests (Harris, 1985).

To account for variations in probe speed, the distance at which fish responded was converted into the apparent looming threshold (ALT) (Dill, 1974; Webb, 1981), which was calculated as:

$$
A L T=(4 U S) /\left(4 D^{2}+S^{2}\right),
$$

where $U$ is probe speed, $S$ is probe diameter and $D$ is the reactive distance of the larva.

\section{Results}

Anatomy

Gas was observed in bullae of menhaden larvae as small as $9 \mathrm{~mm} T L$. Gas was present in the bullae of $50 \%$ of the larvae

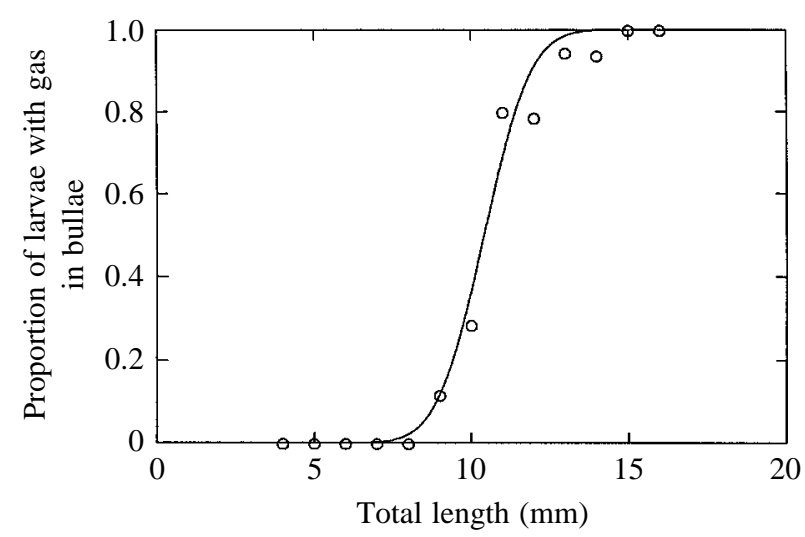

Fig. 1. Inflation of the auditory bullae in menhaden expressed as the proportion in each $1 \mathrm{~mm}$ size class with inflated bullae. Proportions are derived from examination of between 5 and 40 larvae, with more larvae sampled at smaller sizes. The curve was drawn using the equation: proportion inflated $=\mathrm{zcf}\left(B_{0}+\mathrm{B}_{1} \times O_{\mathrm{L}}\right)$, with coefficients determined by a non-linear estimation of the normal cumulative distribution function (see Wilkinson, 1992, for details).

by $11.3 \mathrm{~mm}$ and all larvae had gas in the bullae by $15 \mathrm{~mm}$ (Fig. 1). Once the bullae inflated, they remained inflated throughout the larval period.

The total number of superficial neuromasts increased gradually throughout ontogeny (Fig. 2). In small larvae, the total was evenly partitioned between cephalic and trunk neuromasts. After $15 \mathrm{~mm}$, cephalic neuromasts were slightly more numerous than trunk neuromasts until larvae reached $19 \mathrm{~mm} \mathrm{TL}$. At this size, the number of cephalic superficial neuromasts began to decrease, probably as a result of subsumption of neuromasts into cephalic canals (Hoss and Blaxter, 1982; D. M. Higgs, personal observation).

The densities of cone and rod photoreceptors changed appreciably during ontogeny. Cone density was relatively constant from hatching until $10 \mathrm{~mm} T L$ (Fig. 3), after which it

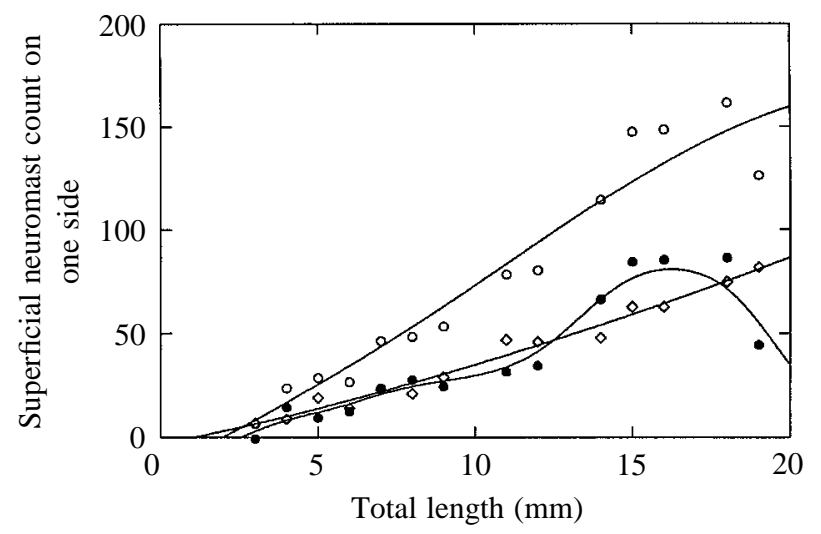

Fig. 2. Proliferation of superficial neuromasts on one side of the body (open diamonds), one side of the head (filled circles) and the body and head together (open circles) in menhaden larvae. Each point represents a composite of at least three fish in each size class. Curves represent a density-weighted least-squares smoothing function (see Wilkinson, 1992) and are not meant to imply statistical significance. 


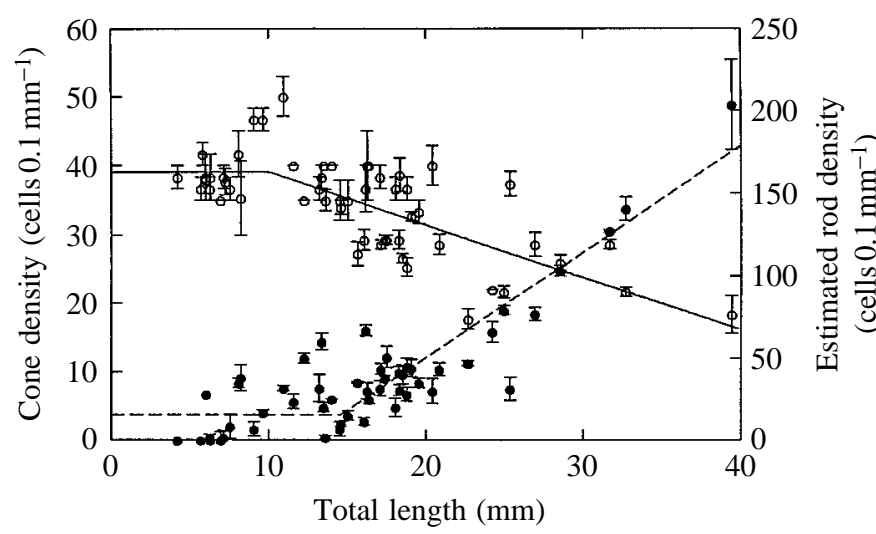

Fig. 3. Ontogenetic changes in the density of cone (open circles, solid line) and rod (filled circles, dashed line) photoreceptors in menhaden larvae. Each point represents the mean ( \pm 1 S.E.M.) photoreceptor density in three retinal sections of one fish. Lines represent piecewise regressions.

decreased from a mean of approximately 40 to 18 cones $0.1 \mathrm{~mm}^{-1}$ by $37 \mathrm{~mm} \mathrm{TL}$. Estimated rod density showed roughly the inverse pattern (Fig. 3). There were no rods evident at hatching in menhaden. Rods first appeared at
8-10 $\mathrm{mm} T L$ and numbers increased gradually until the larvae were $14 \mathrm{~mm}$ long. After $14 \mathrm{~mm}$, rod proliferation was more rapid, exceeding 200 rods $0.1 \mathrm{~mm}^{-1}$ by $37 \mathrm{~mm} \mathrm{TL}$.

Ganglion cell density gradually decreased during ontogeny (Fig. 4A), and the summation ratio of outer nuclear layer to ganglion cell layer cells (ONL/GCL) increased ontogenetically (Fig. 4B). Larvae began to sum visual inputs (ONL/GCL>1.0) at approximately $12-14 \mathrm{~mm} T L$. Larvae longer than $20 \mathrm{~mm}$ had a substantially higher rate of increase in summation ratio. The changes in summation ratio appear to be due primarily to rod, rather than to cone, photoreceptive inputs, especially at larger sizes. The ratio of rod cells to ganglia surpasses unity at $21 \mathrm{~mm}$ and rapidly increases thereafter (Fig. 4C). This is the same general pattern seen for ONL/GCL (Fig. 4C). The ratio of cones to ganglia is much lower than for rods to ganglia and never increases consistently beyond unity (Fig. 4D). This suggests that there is one cone photoreceptor for each ganglion cell but multiple rods (as many as 11) for each ganglion in larger larvae.

The final retinal attribute examined was histological (retinal) acuity (equation 1). Atlantic menhaden have a maximum histological acuity (i.e. smallest minimum separable angle) of approximately $1.8^{\circ}$ at hatching (Fig. 5). This rapidly improves to approximately $0.5^{\circ}$ by $15 \mathrm{~mm} \mathrm{TL}$. Beyond this size, acuity
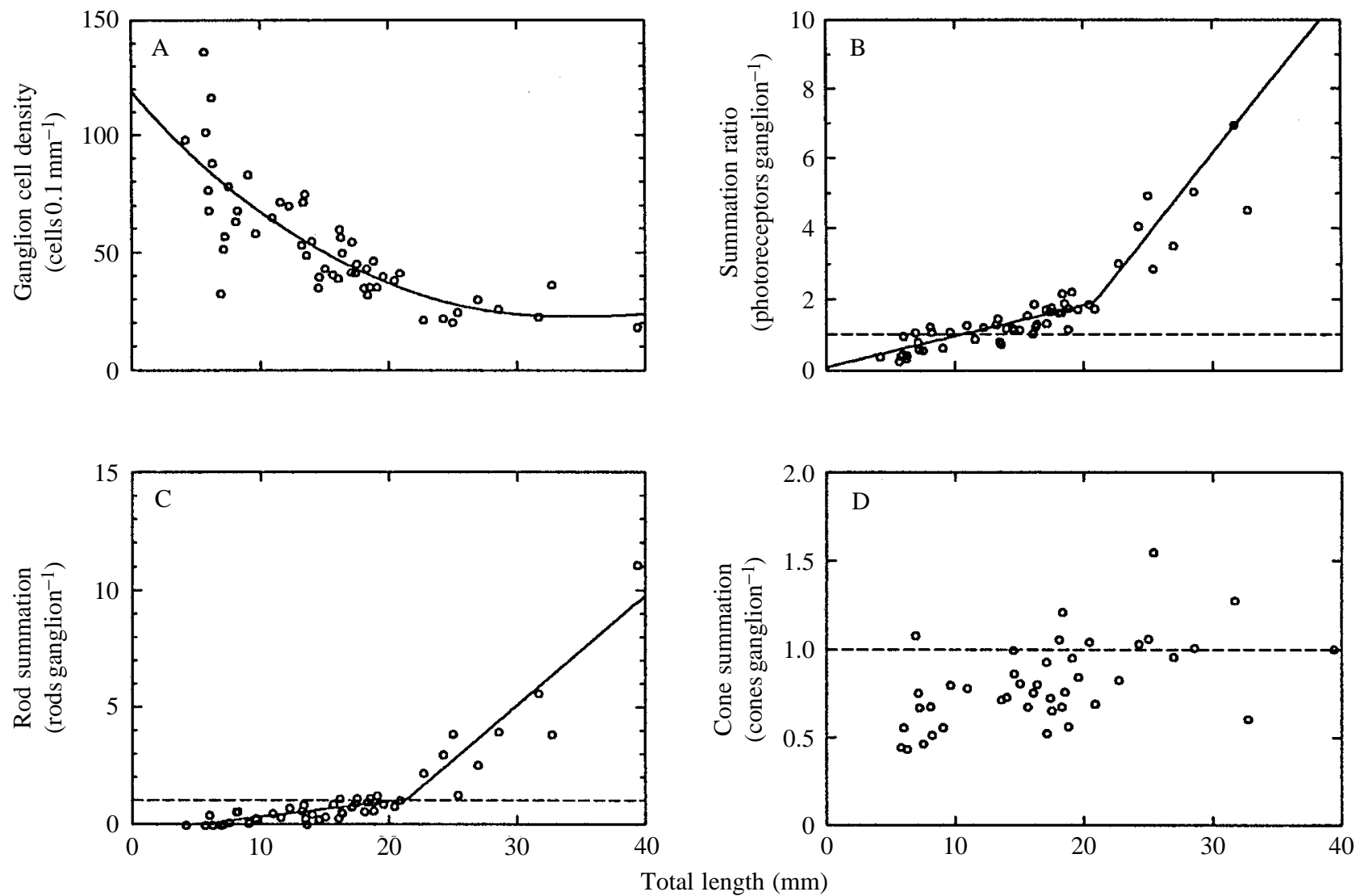

Fig. 4. Ontogenetic changes in (A) ganglion cell density and in the ratio of photoreceptor cell to ganglion cell density for (B) all photoreceptors, (C) rods only and (D) cones only. In B-D, the dashed line equals a ratio of 1.0, where each ganglion is presumed to be innervated by one photoreceptor. Values greater than 1.0 in B-D represent each ganglion being innervated by more than one photoreceptor. Each point represents the mean value for an individual fish. The fitted line in A represents a density-weighted least-squares smoothing function, the fitted lines in B and $\mathrm{C}$ represent piecewise regressions. 


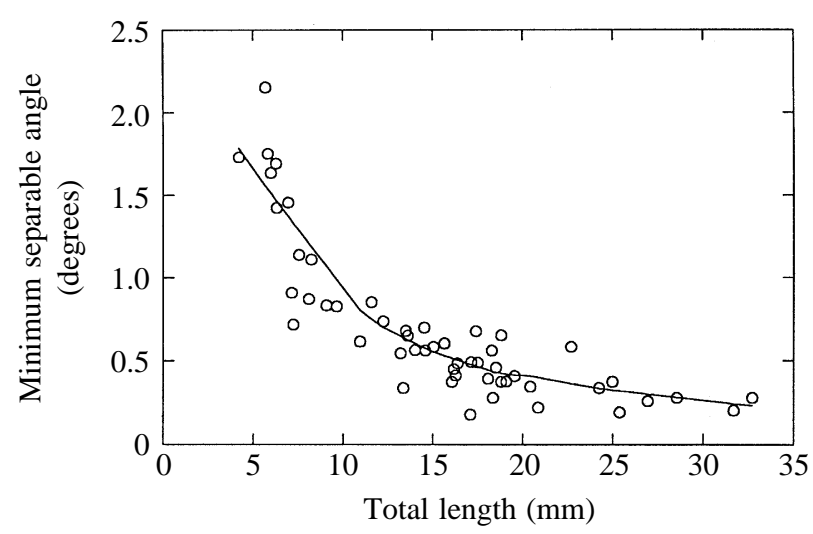

Fig. 5. Retinal (histological) acuity, expressed as the minimum separable angle, based on cone spacing. Each point represents the mean acuity estimate for an individual fish. The curve represents a locally weighted scatterplot smoothing (see Wilkinson, 1992).

improves less rapidly, reaching approximately $0.2^{\circ}$ at $30 \mathrm{~mm}$ $T L$ (Fig. 5).

\section{Behavior}

Menhaden larvae showed a significant $\left(P=0.01, r^{2}>0.99\right)$ ontogenetic increase in the proportion responding to the probe under normal (light-control) conditions (Fig. 6). Just after hatching (5-7 mm TL), 57\% of light-control larvae responded to the probe before it touched them. By $20 \mathrm{~mm} T L, 100 \%$ of these larvae responded. When visual information was withheld from the larvae (dark-controls), the proportion of the larvae responding to the approaching probe decreased (Fig. 6). Although the slope of this line was not statistically significant $\left(P=0.16, r^{2}=0.87\right)$, it was also not significantly different from the trend for light-control larvae $(P=0.42)$. When neuromasts

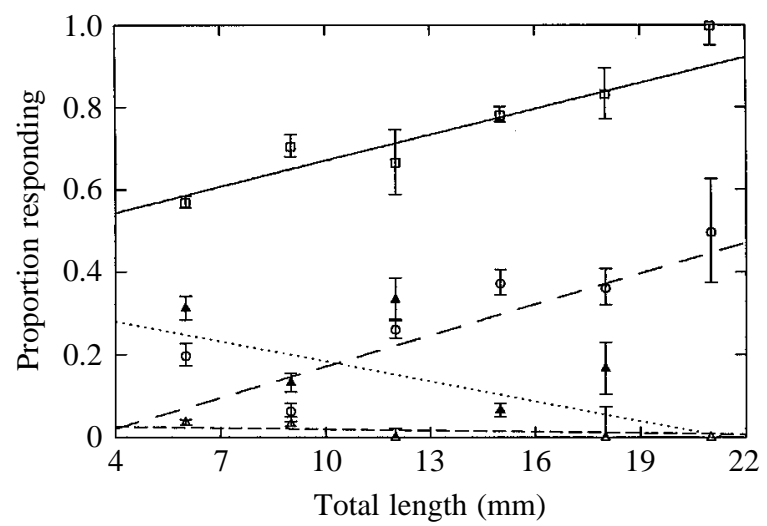

Fig. 6. Responsiveness (expressed as the proportion, \pm 1 S.E.M., of larvae responding) of menhaden larvae exposed to all available sensory stimuli ('light-control'; $N=89$; open squares, solid line), larvae without visual input ('dark-control'; $N=80$; open circles, dashed line), larvae without neuromast input ('light-strep'; $N=61$; filled triangles, dotted line) and larvae with neither visual nor neuromast inputs ('dark-strep'; $N=90$; open triangles, dashed line). Each point is the proportion responding in $3 \mathrm{~mm}$ size classes. Lines represent weighted linear regressions. were not functional (light-strep), there was also a reduction in responsiveness compared with the light-controls (Fig. 6), but there was no ontogenetic change $\left(P=0.26, r^{2}=0.75\right)$. The proportion responding ranged from 0.06 to 0.33 , regardless of larva size. The slope of the relationship was significantly different from that for light-control larvae $(P=0.002)$. When both neuromast and visual inputs were blocked (dark-strep), $0-7 \%$ of the larvae responded to the approaching probe (Fig. 6), with no change as total length increased $(P=0.85$, $r=0.84)$. The slope of this relationship was also significantly different from that seen in light-control trials $(P=0.006)$.

Of the fish that responded to the approaching probe, the reactive distance increased significantly with total length in light-control conditions $\left(P \ll 0.001, r^{2}=0.27\right)$. Mean reactive distance ranged from $1-3 \mathrm{~mm}$ for smallest larvae to $12-19 \mathrm{~mm}$ for the largest larvae in the light-control trials (Fig. 7A). When visual input was withheld from the larvae (dark-controls), the relationship between reactive distance and total length was statistically indistinguishable from that for light-control larvae $(P=0.89)$. The increase in reactive distance with total length in dark-control larvae was not as marked as in light-controls $\left(P=0.06, r^{2}=0.13\right.$, Fig. 7B). Elimination of neuromast input (light-strep) significantly affected the reactive distance of menhaden larvae (Fig. 7C). There was no significant change in reactive distance over ontogeny in light-strep larvae $(P=0.29$, $r^{2}=0.03$ ), and the trend in reactive distance seen in light-strep fish was significantly different from that seen for light-control fish $(P=0.001)$. Mean distances for larvae near $15 \mathrm{~mm} T L$ were approximately half those for light-control fish. Owing to the small number of fish that responded to the approaching probe in the dark-strep treatments $(N=3)$, reactive distance of larvae with no neuromast or visual input were not analyzed statistically. The three dark-strep fish that responded had short reactive distances (Fig. 7D).

The apparent looming threshold (ALT) of light-control larvae decreased rapidly from hatching to $10 \mathrm{~mm} T L$, decreasing more slowly or not at all after $10 \mathrm{~mm}$ (Fig. 8A). Dark-control and light-strep larvae did not show such clear changes. There was no consistent change in $A L T$ with total length in either or these treatments (Fig. 8B,C). Patterns in ALT could not be examined in dark-strep larvae as very few larvae responded to the approaching probe in this treatment (Fig. 8D).

In light-control larvae, behavioral acuity did not reach the levels predicted from anatomical measurements of the retina, i.e. histological acuity (Fig. 9). The acuity based on behavioral data was poorer (larger minimum separable angle) at all sizes than that based on morphology, although at larger sizes behavioral acuity came closer to the morphologically derived values. At the largest sizes tested, morphological acuity was only $3-6^{\circ}$ higher than histological acuity, whereas at hatching, behavioral acuity was $30-50^{\circ}$ higher.

\section{Discussion}

The ontogenetic increase in responsiveness and reactive distance of light-control larvae was due either to an ontogenetic 


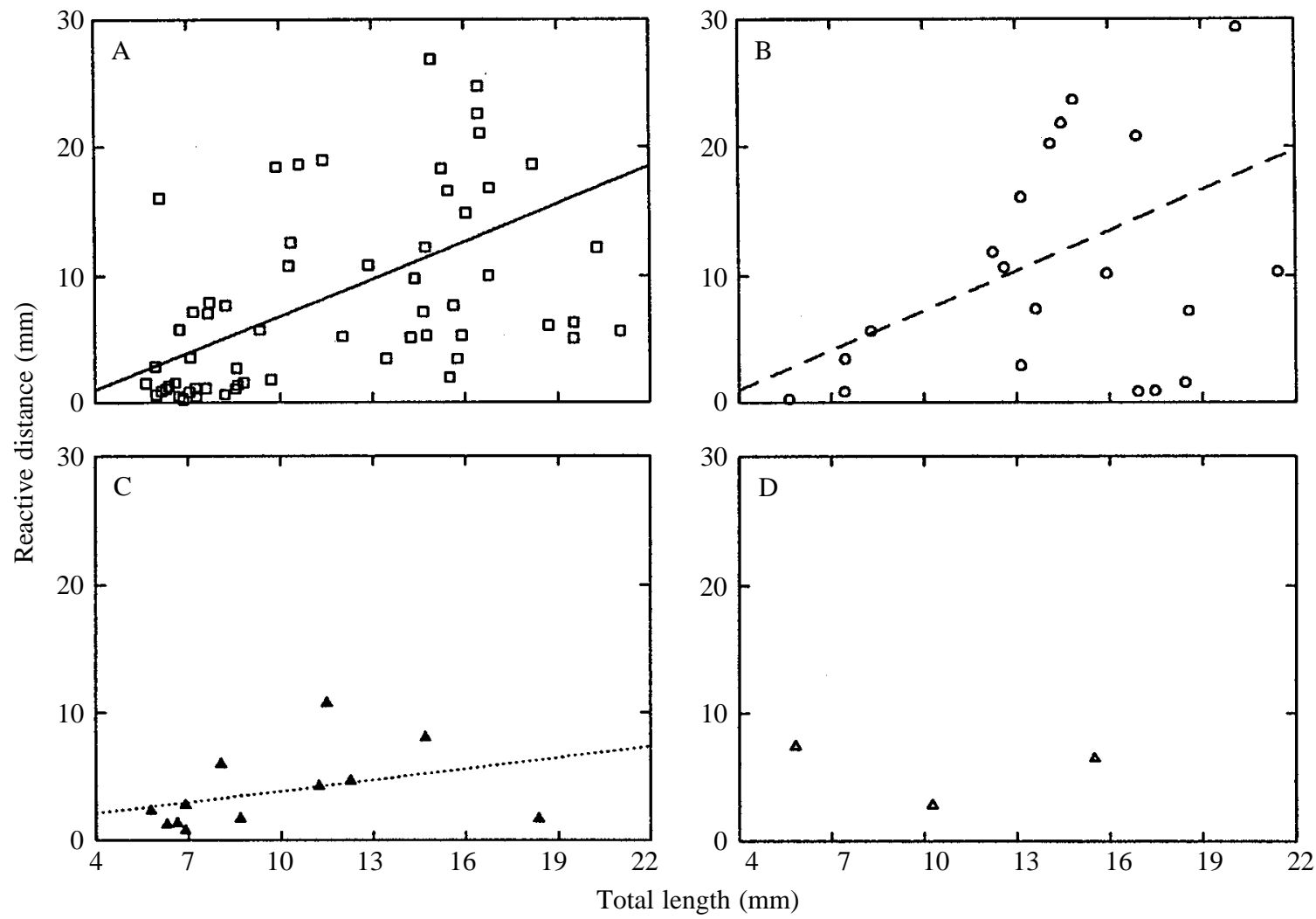

Fig. 7. Ontogenetic changes in reactive distance in (A) larvae exposed to all available sensory stimuli ('light-control'; $N=61$ ), (B) larvae without visual input ('dark-control'; $N=21$ ), (C) larvae without neuromast input ('light-strep'; $N=12$ ) and (D) larvae with neither visual nor neuromast inputs ('dark-strep'; $N=3$ ). Each point represents an individual fish. Lines represent simple linear regressions.

change in the criteria that the larvae used to decide whether to respond to stimuli or to an increased ability to detect and respond to the approaching stimulus. Little is known about what criteria fish use when deciding whether to respond to stimuli. Much more is known about the detection of, and response to, looming stimuli. Changes in the response to, and escape from, predatory stimuli may be due to sensory (Webb, 1981; Blaxter and Fuiman, 1989, 1990; Margulies, 1989) or motor (Eaton and DiDomenico, 1986; Fuiman and Magurran, 1994) development. The current study can only directly address the effects of behavioral changes due to sensory development. As the behavioral responses of these larvae improved, the visual, mechanoreceptive and auditory systems were also undergoing major changes. While some inferences can be drawn by comparing trends in sensory development with behavioral trends in the light-control larvae, the importance of each sensory system is best addressed by examining the responses of larvae when selected inputs were withheld.

The visual system was found to be important for responding to the advancing probe. This is shown by the decrease in responsiveness when visual input was withheld (dark-control) and by the ability of the larvae to respond in the light when neuromasts were ablated (light-strep). The visual system was not shown to be important to reactive distance, however, as there was no discernible difference between dark-control and light-control larvae in this measure of behavior. The developmental changes in the retina did not lead to a significant improvement in either responsiveness or reactive distance, since there was no difference in the rate of change of these measures with growth between light-control and dark-control larvae. This result was unexpected. The menhaden retina was undergoing major changes in cell types, distributions and connectivity and yet development of these cells did not lead to a change in the behaviors measured. It appears that vision is important in determining whether a fish will respond to a stimulus, but that the eye of a newly hatched larval menhaden is as capable as the eye of a late larva for this purpose.

Superficial neuromasts were important in determining both whether a fish responded to a stimulus and when (from how far) the response occurred. When neuromast input was blocked (light-strep), both of these measures of behavior were significantly reduced compared with those of light-control larvae. The ontogenetic increase observed in light-control larvae was not evident in larvae with ablated neuromasts. This suggests that neuromast proliferation was an important component of the ontogenetic increases in responsiveness and reactive distance of light-control larvae. The gradual increases seen in responsiveness and reactive distance of control larvae also matched the gradual nature of neuromast development, 


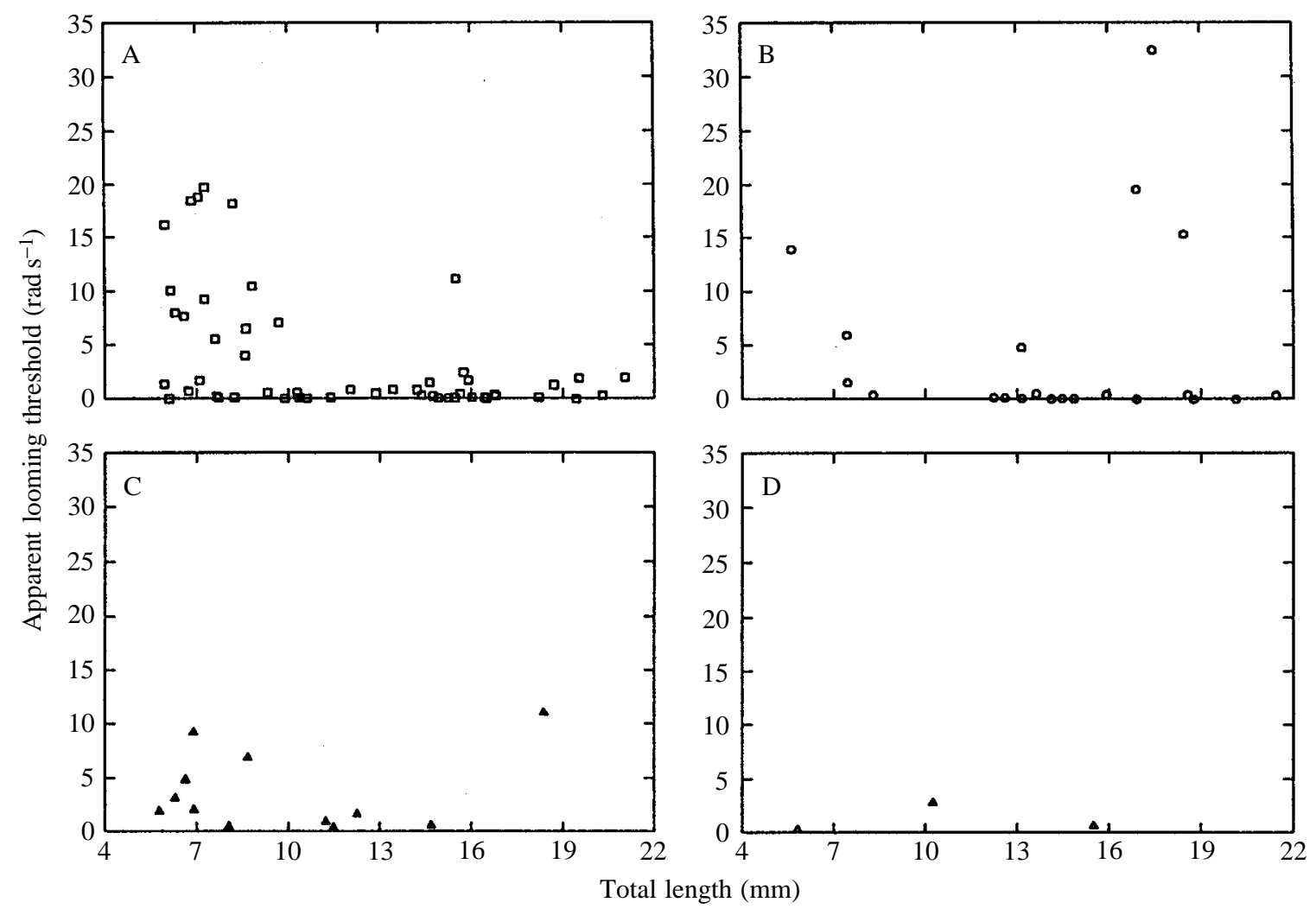

Fig. 8. Apparent looming threshold in (A) larvae exposed to all available sensory stimuli ('light-control'), (B) larvae without visual input ('darkcontrol'), (C) larvae without neuromast input ('light-strep') and (D) larvae with neither visual nor neuromast inputs ('dark-strep'). Each point represents an individual fish. Numbers of fish in each treatment are the same as for Fig. 7.

providing circumstantial evidence for the importance of neuromast number to the presence and timing of a response. Few other studies have explicitly tested the functional role of neuromasts in larvae. Blaxter and Fuiman (1989) showed reduced responsiveness to a probe in Atlantic herring (Clupea harengus) larvae treated with streptomycin compared with control larvae. Blaxter and Fuiman (1990), however, found no effect of streptomycin treatment in herring being attacked by a natural predator until the herring developed cephalic lateral line canals. Once canals had been formed, streptomycin treatment did reduce responsiveness of larval herring to nonthreatening encounters with predatory fish.

Inflation of the auditory bullae had no effect on responsiveness or reactive distance of menhaden larvae. Blocking both visual and mechanoreceptive inputs (dark-strep) left larvae unresponsive to the probe. There was no difference in responsiveness of dark-strep larvae before and after bulla inflation nor was there a change in either of these behavioral measurements coincident with bulla inflation in any of the other treatments. In contrast, Atlantic herring larvae show a dramatic increase in responsiveness to natural predators after bulla inflation (Fuiman, 1989; Blaxter and Fuiman, 1990). Inflation of the bulla also improves detection of acoustic stimuli in herring (Blaxter and Batty, 1985). The menhaden may not have used their bullae to respond in the present study owing to the nature of the stimulus used. Sound waves created by the probe may have had small pressure components. The bulla is more sensitive to variations in pressure than to variations in displacement (Blaxter and Batty, 1985) and thus may not have been stimulated in our study.

It is interesting to note that the combined responsiveness of larvae in the dark-control and light-strep treatments did not

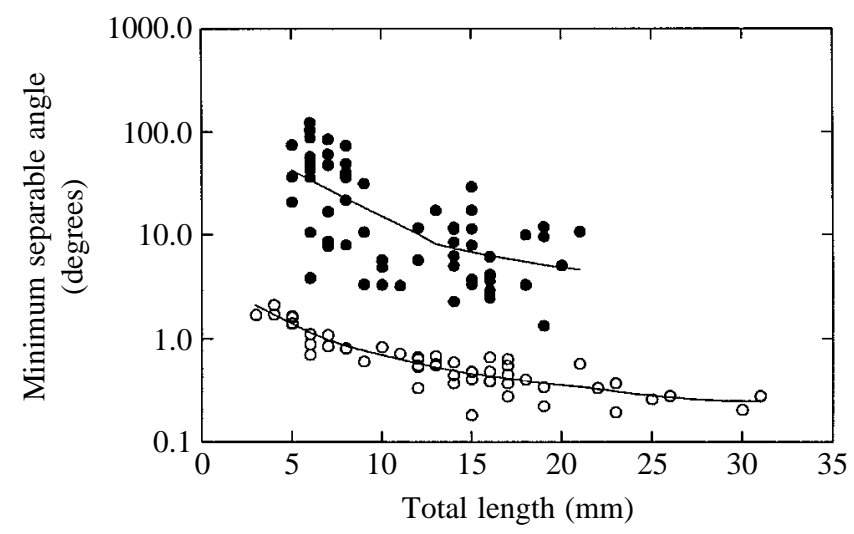

Fig. 9. Ontogenetic changes in visual acuity of menhaden larvae based on histological (open circles) and behavioral (filled circles) methods. The curve for histological acuity represents a density-weighted leastsquares smoothing function while that for behavioral acuity represents a locally weighted scatterplot smoothing function (see Wilkinson, 1992). 
equal the responsiveness of larvae in the light-control treatment (Fig. 6). This suggests that the integration of visual and mechanoreceptive stimuli in the brain of these larvae is not simply an additive process. Tectal integration of sensory stimuli by bimodal neurons can result in a change in stimulus strength relative to the sum of unimodal responses in electric fishes (Apteronotus albifrons; Bastian, 1982) and in rattlesnakes (Crotalus viridis; Newman and Hartline, 1981). The ontogeny of these tectal cells has not been studied in menhaden larvae, but the tectum is well differentiated shortly after hatching in this species (D. M. Higgs, personal observation). The behavioral responsiveness data presented here suggest that the neurons responsible for integrating different types of stimuli are present throughout the larval period, although direct anatomical observation is necessary before this can be stated with certainty.

The decreasing trend in $A L T$ with total length in light-control larvae is very similar to that seen in northern anchovy (Engraulis mordax) larvae attacked by a real predator (Webb, 1981). This suggests that our artificial stimulus elicited responses similar, on some levels, to the responses elicited by an actual predator. The $A L T$ was derived from principles of optics and has traditionally been considered for solely visual stimuli (Dill, 1974; Webb, 1981). In the present study, the trend in $A L T$ with total length was different from control values when either visual or neuromast information was withheld (Fig. 8B,C). This suggests that the ALT may be applicable for non-visual stimuli, as long as the stimulus strength increases with the size and closing speed of its source.

The unintended increases in probe speed with total length might be interpreted as the reason for the behavioral patterns observed in the present study. Several pieces of evidence suggest that this was not the case. The lack of a difference in probe speed between responding and non-responding larvae suggests that the ontogenetic changes in responsiveness were not an artifact of the increasing probe speed with total length. Probe speed did not affect reactive distance in light-control or dark-control larvae, suggesting that the differences seen here were real. Finally, if the speed of the approaching probe caused the behavioral differences observed in the present study, lightstrep larvae should have been the least responsive, as the probe speed was lowest in this treatment. Instead, light-strep larvae were more responsive than dark-strep larvae, although darkstrep probe speeds were higher. While it was not without problems, the manually advanced probe was a suitable method for assessing the role of each sensory system in isolation and in conjunction with the other sensory systems.

The changes and differences observed in histological and behavioral acuity are similar to those found for other fishes. Newly hatched fishes of many species have a histological acuity of $1-2^{\circ}$ (Neave, 1984; Pankhurst et al. 1993), matching well the value of $1.7^{\circ}$ found in our menhaden larvae. As teleost larvae develop, histological acuity improves gradually, with the values obtained for menhaden in this study being similar to those for other species (Neave, 1984; Pankhurst et al. 1993; Miller et al. 1993). Behavioral acuities are more variable and may be dependent upon the methods used to obtain them. Acuities range from $30-40^{\circ}$ at hatching to $2.0-0.4^{\circ}$ at metamorphosis in the few species that have been examined (Neave, 1984; Pankhurst et al. 1993; Miller et al. 1993). All studies, including the present one, found histological acuity significantly better than behavioral acuity at small sizes. This was true regardless of the technique used to estimate behavioral acuity. Suggestions for this disparity include myopia of early larvae (Pankhurst et al. 1993), changes in connectivity of the optic tectum (Rahmann et al. 1979), suboptimal laboratory conditions (Miller et al. 1993) and summation of photoreceptors into ganglia (Browman et al. 1990). It is also possible that we could have underestimated behavioral acuity if there was a substantial latency to the responses we observed. All the possible explanations for the disparity could apply to the present study, although summation would not be important until menhaden reached approximately $14 \mathrm{~mm}$ in $T L$ (Fig. 4B). It seems likely that changes in retinal connectivity and focusing ability, as well as in larval motivation, would contribute to disparities between histological and behavioral acuity.

Some of the anatomical variables measured here showed abrupt changes during ontogeny. Bulla inflation (Fig. 1), rod density (Fig. 3) and retinal summation (Fig. 4B) increased rapidly after $15-20 \mathrm{~mm} T L$. By $21 \mathrm{~mm} T L$, the responsiveness of light-control larvae reached a proportion of 1.0 (Fig. 6). These changes occurred at a size at which this species begins to experience a major change in habitat. Menhaden spawn offshore, and the larvae do not arrive in estuarine environments until a mean standard length $(S L)$ of $24.6 \mathrm{~mm}$, with the smallest larvae entering the estuary in appreciable numbers at $15 \mathrm{~mm}$ SL (Warlen, 1994). This is equivalent to a mean total length of $29.2 \mathrm{~mm}$ and a minimum of $16.4 \mathrm{~mm} T L$ using the relationship $S L=1.35 \times T L^{0.86}$ (empirically derived from drawings in Jones et al. 1978). The ontogenetic changes documented in the current study therefore occur just before menhaden larvae arrive inshore. As menhaden migrate to coastal waters, they are exposed to a higher density of potential predators (Morgan, 1990). We hypothesize that the ontogenetic changes menhaden experience before arriving inshore reduce their susceptibility to predators in the estuarine environment. If our hypothesis is correct, closely related inshore species should develop rods, sum retinal inputs and fill the bullae with gas earlier in development than menhaden. Related inshore species should also be more responsive to predatory stimuli as larvae. Menhaden should reach the anatomical and behavioral condition of inshore larvae when or before they arrive inshore. This hypothesis is currently being tested in our laboratory by comparing the anatomical and behavioral development of Atlantic menhaden with those of two clupeoid species that live inshore throughout their larval period.

We wish to thank W. Hettler and J. Burke of the National Marine Fisheries Service-Beaufort Laboratory for supplying menhaden eggs used for this project. We also thank K. R. Poling, M. A. Ali, R. W. Hill, C. R. Arnold, E. J. Buskey, J. 
N. Cameron, G. J. Holt and M. J. Ryan for advice throughout the study. This study was supported by a fellowship to D.M.H. from the Electric Power Research Institute and the Sport Fishing Institute. Contribution no. 977 of the University of Texas at Austin, Marine Science Institute.

\section{References}

Allen, J. M., Blaxter, J. H. S. And Denton, E. J. (1976). The functional anatomy and development of the swimbladder-inner ear-lateral line system in herring and sprat. J. mar. biol. Ass. U.K. 56, 471-486.

BAILEY, K. M. (1984). Comparison of laboratory rates of predation on five species of marine fish larvae by three planktonic invertebrates: effects of larval size on vulnerability. Mar. Biol. 79, 303-309.

BAILEY, K. M. AND BATTY, R. S. (1984). Laboratory study of predation by Aurelia aurita on larvae of cod, flounder, plaice and herring: development and vulnerability to capture. Mar. Biol. 83, 287-291.

Bailey, K. M. And Houde, E. D. (1989). Predation on eggs and larvae of marine fishes and the recruitment problem. Adv. mar. Biol. 25, $1-83$.

BAstian, J. (1982). Vision and electroreception: integration of sensory information in the optic tectum of the weakly electric fish Apteronotus albifrons. J. comp. Physiol. 147, 287-297.

BATTY, R. S. (1983). Observation of fish larvae in the dark with television and infrared illumination. Mar. Biol. 76, 105-107.

BlaXter, J. H. S. (1968). Visual thresholds and the spectral sensitivity of herring larvae. J. exp. Biol. 48, 39-53.

BLAXTER, J. H. S. (1986). Development of sense organs and behaviour of teleost larvae with special reference to feeding and predator avoidance. Trans. Am. Fish. Soc. 115, 98-114.

BlaXter, J. H. S. (1991). Sensory systems and behaviour of larval fish. In Marine Biology: Its Accomplishment and Future Prospect (ed. J. Mauchline and T. Nemoto), pp. 15-38. New York: Elsevier Publishing.

Blaxter, J. H. S. And Batty, R. S. (1985). The development of startle responses in herring larvae. J. mar. biol. Ass. U.K. 65, 737-750.

Blaxter, J. H. S. and Fuiman, L. A. (1989). Function of the free neuromasts of marine teleost larvae. In The Mechanosensory Lateral Line: Neurobiology and Evolution (ed. S. Coombs, P. Görner and H. Münz), pp. 481-499. New York: Springer-Verlag.

BlaXter, J. H. S. AND Fuiman, L. A. (1990). The role of the sensory systems of herring larvae in evading predatory fishes. J. mar. biol. Ass. U.K. 70, 413-427.

Blaxter, J. H. S., Gray, J. A. B. And Best, A. C. G. (1983). Structure and development of the free neuromasts and lateral line system of the herring. J. mar. biol. Ass. U.K. 63, 247-260.

BlaXter, J. H. S. AND Hunter, J. R. (1982). The biology of clupeoid fishes. Adv. mar. Biol. 20, 1-223.

BlaXter, J. H. S. AND Jones, M. P. (1967). The development of the retina and retinomotor responses in the herring. J. mar. biol. Ass. U.K. 47, 677-697.

BoeHLERT, G. W. (1979). Retinal development in postlarval through juvenile Sebastes diploproa: adaptations to a changing photic environment. Rev. Can. Biol. 38, 265-280.

Browman, H. I., Gordon, W. C., Evans, B. I. And O'Brien, W. J. (1990). Correlation between histological and behavioral measures of visual acuity in a zooplanktivorous fish, the white crappie (Pomoxis annularis). Brain Behav. Evol. 35, 85-97.
Carleton, H. M. (1957). Histological Techniques for Normal and Pathological Tissue and the Identification of Parasites. 3rd edn. London: Oxford University Press.

Clarke, P. G. H. And Oppenheim, R. W. (1995). Neuron death in vertebrate development: in vivo methods. Meth. Cell Biol. 46, 277-321.

DiLl, L. M. (1974). The escape responses of the zebra danio (Brachydanio rerio). I. The stimulus for escape. Anim. Behav. 22, 711-722.

EAton, R. C. AND DiDomenico, R. (1986). Role of the teleost escape response during development. Trans. Am. Fish. Soc. 115, 128-142.

FOLKVORD, A. AND HunTER, J. R. (1986). Size-specific vulnerability of northern anchovy, Engraulis mordax, larvae to predation by fishes. Fishery Bull. Fish Wildl. Serv. U.S. 84, 859-869.

FuIMAN, L. A. (1989). Vulnerability of Atlantic herring larvae to predation by yearling herring. Mar. Ecol. Prog. Ser. 51, 291-299.

Fuiman, L. A. (1993). Development of predator evasion in Atlantic herring, Clupea harengus L. Anim. Behav. 45, 1101-1116.

FuIMAN, L. A. (1994). The interplay of ontogeny and scaling in the interactions of fish larvae and their predators. J. Fish. Biol. 45, 55-79.

Fuiman, L. A. And MagurRan, A. E. (1994). Development of predator defences in fishes. Rev. Fish Biol. Fish. 4, 145-183.

GERKING, S. D. AND RAUSCH, R. R. (1979). Relative importance of size and chronological age in the life programme of fishes. Arch. Hydrobiol. 13, 181-194.

GuNDERSEN, H. J. G. (1977). Notes on the estimation of the numerical density of arbitrary profiles: the edge effect. J. Microsc. 111, 219-223.

Hagedorn, M. And Fernald, R. D. (1992). Retinal growth and cell addition during embryogenesis in the teleost, Haplochromis burtoni. J. comp. Neurol. 321, 193-208.

Harris, R. J. (1985). A Primer of Multivariate Statistics. Orlando, Florida: Academic Press, Inc.

Hoss, D. E. AND BlaXter, J. H. S. (1982). Development and function of the swimbladder-inner ear-lateral line system in the Atlantic menhaden, Brevoortia tyrannus (Latrobe). J. Fish Biol. 20, 131-142.

Hunter, J. R. (1981). Feeding ecology and predation of marine fish larvae. In Marine Fish Larvae. Morphology, Ecology and Relation to Fisheries (ed. R. Lasker), pp. 33-77. Seattle: Washington Sea Grant Program.

Jones, P. W., Martin, F. D. And Hardy, J. D., JR (1978). (eds). Development of Fishes of the Mid-Atlantic Bight, vol. I, Acipenseridae through Ictaluridae. Fish and Wildlife Service, US Department of the Interior.

Kaus, S. (1987). The effect of aminoglycoside antibiotics on the lateral line organ of Aplocheilus lineatus (Cyprinodontidae). Acta otolaryngol. 103, 291-298.

Margulies, D. (1989). Size-specific vulnerability to predation and sensory system development of white seabass, Atractoscion nobilis, larvae. Fishery Bull. Fish Wildl. Serv. U.S. 87, 537-552.

Matsuura, S., IKedA, K. AND Furukawa, T. (1971). Effects of streptomycin, kanamycin, quinine and other drugs on the microphonic potentials of goldfish sacculus. Jap. J. Physiol. 21, 579-590.

Matthiessen, L. (1880). Untersuchungen über den Aplanatismus die Periscopie der Krystalllinsen in den Augen der Fische. Pflügers Arch. Gesamte Physiol. Menschen Tiere. 21, 287-307. As cited in: Neave, D. A. (1984). The development of visual acuity in larval plaice (Pleuronectes platessa L.) and turbot (Scophthalmus maximus L.). J. exp. mar. Biol. Ecol. 78, 167-175. 


\section{Ontogeny of visual and mechanosensory function in menhaden 2629}

Miller, T. J., Crowder, L. B. ANd Rice, J. A. (1993). Ontogenetic changes in behavioral and histological measures of visual acuity in three species of fish. Env. Biol. Fish. 37, 1-8.

Morgan, S. G. (1990). Impact of planktivorous fishes on dispersal, hatching and morphology of estuarine crab larvae. Ecology 71, 1639-1652.

Mukai, Y., Kobayashi, H. and YoshiKawa, H. (1992). Development of free and canal neuromasts and their directions of maximum sensitivity in the larva of ayu, Plecoglossus altivelis. Japan. J. Ichthyol. 38, 411-417.

Neave, D. A. (1984). The development of visual acuity in larval plaice (Pleuronectes platessa L.) and turbot (Scophthalmus maximus L.). J. exp. mar. Biol. Ecol. 78, 167-175.

Newman, E. A. AND Hartline, P. H. (1981). Integration of visual and infrared information in bimodal neurons of the rattlesnake optic tectum. Science 213, 789-791.

O'Connell, C. P. (1981). Development of organ systems in the northern anchovy, Engraulis mordax and other teleosts. Am. Zool. 21, 429-446.

Pankhurst, P. M., Pankhurst, N. W. and Montgomery, J. C. (1993). Comparison of behavioural and morphological measures of visual acuity during ontogeny in a teleost fish, Fosterygion varium, Tripterygiidae (Foster, 1801). Brain Behav. Evol. 42, 178-188.

Pepin, P., Pearre, S., JR And Koslow, J. A. (1987). Predation on larval fish by Atlantic mackerel, Scomber scombrus, with a comparison of predation by zooplankton. Can. J. Fish. aquat. Sci. 44, 2012-2018.

PfeILER, E. (1989). Sensory systems and behavior of premetamorphic and metamorphic leptocephalous larvae. Brain Behav. Evol. 34, 25-34.

RAhMANN, H., Jeserich, G. AND ZeUtZius, I. (1979). Ontogeny of visual acuity of rainbow trout under normal conditions and light deprivation. Behaviour 68, 315-322.

TAYlor, E. B. AND MCPhaIL, J. D. (1985). Ontogeny of the startle response in young coho salmon Oncorhynchus kisutch. Trans. Am. Fish. Soc. 114, 552-557.

WARLEN, S. M. (1994). Spawning time and recruitment dynamics of larval Atlantic menhaden, Brevoortia tyrannus, into a North Carolina estuary. Fishery Bull. Fish Wildl. Serv. U.S. 92, 420-433.

WeBb, J. F. (1989). Neuromast morphology and lateral line trunk canal ontogeny in two species of cichlids: an SEM study. J. Morph. 202, 53-68.

Webb, P. W. (1981). Responses of northern anchovy, Engraulis mordax, larvae to predation by a biting planktivore, Amphiprion percula. Fishery Bull. Fish. Wildl. Serv. U.S. 79, 727-735.

WERSÄLL, J. AND FLOCK, Å. (1964). Suppression and restoration of the microphonic output from the lateral line organ after local application of streptomycin. Life Sci. 3, 1151-1155.

WILKINSON, L. (1992). SYSTAT: The System for Statistics. Evanston, IL: SYSTAT Inc.

Yin, M. C. AND BlaXTER, J. H. S. (1987). Escape speeds of marine fish larvae during early development and starvation. Mar. Biol. 96, 459-468.

ZAR, J. H. (1984). Biostatistical Analysis, 2nd edn. Englewoods Cliffs, NJ: Prentice-Hall. 